Tagma, H. (2021). Teaching Theory and Space: Human Territoriality in Political

Science. PS: Political Science \& Politics, 54(4), 767-771.

doi:10.1017/S1049096521000688

Halit M. E. Tagma is an assistant professor in the Department of Politics and International Affairs at Northern Arizona University, Flagstaff, AZ. He can be reached at Halit.Tagma@nau.edu.

\title{
Teaching Theory and Space: Human Territoriality in Political Science
}

Learning theories in political science can be difficult for students. The manuscript shares a technique to help students understand how a theory on human characteristics may impact behavior. I use a mini-simulation where two volunteers are asked to enact a gimmick in front of the classroom, demonstrating the theory of human territoriality (Asal et al. 2018). While the volunteers engage in small talk, the instructor points out that they engage with one another at a certain distance and angle that reflects social space. As the exercise progresses, students easily relate to the theory of human territoriality, defined as the symbolic and physical connection to a space considered as one's own. This mini-simulation achieves the following learning objectives that a) theories are very relevant and help explain human behavior, b) the workings of the individual-level of analysis, and c) theories are not universal and have limits in their application across culture, time, and space. This teaching technique requires no preparation time and resources, and students easily comprehend the expected learning outcomes. Having received overwhelmingly positive feedback in evaluations, I share this as a viable technique for teaching theory in general as it helps students comprehend what a theory is supposed to do - that is, to understand, explain, and sometimes predict behavior.

Learning theories in political science asks students to think abstractly about, for example, the psychological characteristics of humans, the mode of organization of societies, and the effects of systems and structures on behavior. Thinking abstractly about behavior and politics may be difficult for students. Traditionally, instructors have sought to achieve learning objectives with lectures and assignments. Teaching a generation of students exposed to numerous forms of social media is a task that needs reassessment and adaptation on the part of instructors to increase attention and retention. Resorting to different techniques and teaching styles such as gimmicks and simulations makes it easier for a generation of students whose window of attention span is 
becoming narrower (Guàrdia, Maina and Sangrà 2013). As Asal and Blake suggest: "simulations

offer social science students an opportunity to learn from first-hand experience in much the same way that laboratory experiments allow students of the physical sciences to observe actual physical processes...[this] helps to increase students' understanding of the subtleties of theories or concepts"(2006, 1).

This mini-simulation illustrates the theory of human territoriality in international relations, which suggests that humans attach symbolic meaning to a physical space they feel ownership over. This theory is used at the individual level of analysis that focuses on human psychological sources of behavior. This activity can also be used to create similar classroom experiences to teach theory in general, regardless of the sub-field in political science.

\section{Using Different Teaching Techniques}

Simulations, mini-games, and gimmicks encourage students to empathize with different subject positions and distance themselves from that particular subjectivity during the debriefing stage. Such techniques require the participation of students and observers by playing assigned roles (Asal et al. 2013). Building on Schacht and Stewart (1990;1992), Asal suggests the use of gimmicks as a "user-friendly and interactive approach" where "students themselves are the data points or objects of theory applications" (Asal et al. 2018, 2). A quantitative study shows that "students learn more initially from a lecture, but that students who were exposed to the simulation were better able to retain that information over the long-term"(Wunische 2019, 37). Additionally, Frederking's (2005), Baranowski and Weir's (2015), and Shellman and Turan's (2006) quantitative studies on the effectiveness of simulations on student learning outcomes lend credence to using them in our classrooms. 
The benefits of using different teaching strategies include increasing student engagement, retaining more of the material (Omelicheva and Avdeyeva 2008), and attracting new majors (Shellman and Turan 2006). Among the many examples of different teaching techniques, political scientists have used them to teach collective-action problems and role-playing in diplomacy (Ellington, Grillo, and Shaw 2006; Hamilton 2020), world hunger (Krain and Shadle 2006), multilateral bargaining (Shellman and Turan 2006), EU decision-making (Jones and Bursens 2015), election campaigns (Caruson 2005), and crises (Butcher 2012; Glasgow 2014; Taylor 2013).

\section{The Theory of Human Territoriality}

A challenge in teaching theory is to get students to think conceptually and theoretically, which requires instructors to appeal to what Bloom refers to as higher learning skills as abstraction and evaluation (Krathwol 2002). While explaining theories of international relations [IR], I utilize the commonly used levels of analysis (i.e., "images") to help students understand the causes and sources of behavior. To teach the second and third levels (state, system), I use examples of different theories that are relatively straightforward. However, teaching first-level theories (human characteristics) as a cause of conflict can be challenging for students who may wander off on different tangents. Teaching the first-level asks students to think about human subjectivity and psychology as a potential cause of behavior.

This article shares a mini-simulation at the individual-level of analysis. I used this technique across different cultures and based on the positive reception of students in evaluations, and I have improved on it over fifteen years. This "organic simulation" exemplifies the workings of the theory of human territoriality with the assistance of volunteers in the classroom (Kollars 
and Rosen 2013). During the simulation, the volunteers interact with one another and unintentionally reveal to the audience that they carry social spaces around themselves. As a scholar who teaches both mainstream and critical approaches in IR, this mini-simulation achieves the following learning objectives: a) theories are very relevant and help explain human behavior, b) the workings of the individual-level of analysis, and c) theories are not universal and have limits in their application across culture, time, and space. Accordingly, the article contributes to a growing literature on alternative teaching methods.

The theory of territoriality has roots in anthropology, psychology, and sociology and has been used by political scientists (Johnson and Toft 2014; Sack 1986). The literature points out anthropological and psychological explanations of the causes of behavior, making it a useful example of a theory located at the first-level of analysis. A classic study refers to a territory as “an area occupied exclusively by [subjects] means of repulsion through overt defense or advertisement. This definition emphasized the behavioral basis of territoriality without overemphasizing one possible mechanism of spacing at the expense of other possibilities (e.g., mutual avoidance based on olfactory or visual markings)" (Dyson-Hudson and Smith 1978, 23).

Several scholars have studied territoriality in international conflict. In their quantitative studies, Senese and Vasquez suggest that territorial claims and disputes make militarized interstate disputes more likely (2003, 2008; Vasquez 1995). For Huth, territoriality is a factor that must be analyzed in the broader framework of foreign policy $(2009,6)$. Accordingly, Huth and Allee use territorial disputes to theorize about second-image explanations of interstate conflicts by analyzing international legal rulings and scrutinizing the democratic peace theory (2004, 2006). These works suggest that territoriality can also be used as a psychological foundation for second-image theorizing. ${ }^{1}$ Teaching the theory of territoriality also lays the 
foundation for future topics in class that focus on the historical transformation of political space, organizational turf wars, and the development of ideologies as nationalism. For example, the Westphalian sovereign state model transformed medieval notions of space to a territorial statehood that forms the basis of the modern international system (Ruggie 1993; Tagma and Lenze 2020).

\section{The Mini-Simulation}

The class starts with introducing the levels of analysis and how it is used to break down the sources of behavior. I then briefly define the individual-level of analysis without mentioning territoriality yet, because volunteers should not be primed for pedagogical purposes. Used as an example of a theory at the first-level, territoriality argues that human beings attach psychological importance to physical space as they regard it as their own. Put simply, the theory argues that individuals have invisible spaces they carry around themselves. Rather than rely on a standard lecture, the mini-simulation is visually appealing and allows students for a hands-on approach to understanding the theory.

Before I start lecturing on territoriality, I ask for two volunteers in the classroom to come up to the board and engage in a simple performance. ${ }^{2}$ Volunteers are asked to assume they met for the first time at a social event and should engage in friendly small talk such as the weather, reality TV, or sports. I ask the volunteers to simply start talking. I inform them that I will be going to the computer for the next couple of minutes to find a PowerPoint slide for the topic that proceeds. At this point, I stop engaging the volunteers and appear to mind my own business on the computer. Instructors should give them the feeling that they are on their own and the instructor is not looking at them. To make this simulation further enjoyable, instructors can tailor 
and tweak this exercise as they see fit. For example, the instructor can ask the volunteers to assume that we are currently at a social event and the instructor is the host. The instructor can say, for example, "Hey, thanks for coming! You both just arrived. Why don't you introduce yourselves to one another, and I'll fetch some chips and salsa from the kitchen?" The rest of the class finds this entertaining as volunteers start to engage in a fun conversation. Throughout my experience, I found that volunteers tend to be more extroversive and they find it easy to start engaging in a conversation while others are watching.

After about two minutes, the volunteers are relaxed and are organically enjoying their small talk while the classroom is attuned to their conversation. What follows is a crucial point. Instructors who want to use this technique need to come back at the right moment where they take a pause in their conversation. Once I find the right moment, I return and kindly ask the volunteers to freeze and retain their exact physical distance and posture. I gently repeat the request and ask them to hold their position for several minutes as this is a crucial point for the exercise. I then give a brief synopsis of the theory of territoriality and underline how humans carry social spaces around themselves. Next, I show Figure 1 on the PowerPoint. This image is a bird's eye view of two individuals' physical distance from one another with a roughly 20-45degree angle.

\section{[Place Figure 1 Here]}

The image reflects the relative physical distance and angle of the volunteers. Students understand that the image was made beforehand and predicts the volunteers' relative distance and angle. By this time, the classroom is highly engaged, and both the volunteers and the class are 
fascinated by the image and its resemblance with actual behavior. This becomes the perfect learning moment for the instructor as all students are paying very close attention. ${ }^{3}$

As Asal and Kratoville $(2013,132)$ argue, "effective simulations are designed to strike a balance between students' perceptions on what happened and [compare it with the] existing theory as to why it happened." I ask students in the classroom what might be a possible explanation for this resemblance. I proceed to show how human beings create social spacing associated with their comfort zone. If PowerPoint is not accessible, instructors can draw Figure 1 on the board while the volunteers are talking. As illustrated in the image, this space is usually a bit more in front of the individual and a little less in the back. Usually, when human beings engage in a friendly conversation, they talk with one another several feet apart with a degree of angle that respects each other's space in front of them. I then point out that humans may find it uncomfortable if an individual enters too close in their personal space triggering a 'fight or flight instinct.' I show how human beings attach meaning to the physical space around them. I then talk about how a similar logic also applies to facial directions in a crowded elevator. For example, after entering an elevator, most people turn around to face the door. To make the learning experience even more enjoyable, I show a short clip from the show Seinfeld in an episode where a character called 'close talker' illustrates the logic behind the theory of territoriality. ${ }^{4}$ Instructors may also use the 'drill sergeant' image from the movie Full Metal Jacket where the sergeant gets into the face of recruits.

The lecture continues to make this exercise relevant to the first-level of analysis and gives examples from international conflict. One example is the Falkland/Malvinas Islands war in the South Atlantic between the UK and Argentina in 1982. I mention how in the absence of a strong economic/geopolitical interest, Argentina had regarded the Falkland/Malvinas Islands as part of 
its territory and took over the islands under British sovereignty. This created an emotional stir within the British public and was used as a rallying call to protect overseas territories. The instructor can show newspaper headlines from the start of the war to highlight the psychological and emotional aspects involved (Johnson and Toft 2014). ${ }^{5}$

At this point, students are excited and paying very close attention, so I find it helpful to introduce the relative power of theories because it can help us understand and predict behavior. As Wedig (2010) argues, instructors should develop diverse strategies to maximize the learning outcomes of simulations. After outlining what a theory is at the individual-level, students have a much better understanding of what a theory is in general and what it is supposed to dounderstand, explain, and sometimes predict behavior. I also remind students that this theory is not exhaustive of other possible explanations of why conflicts happen. Instructors can mention how territories get socially constructed in the modern age by ideologies as nationalism (Anderson 2006). One can also bring up turf wars in bureaucracies as an example (Allison and Zelikow 1999).

I find it beneficial to open up my lectures to a critical conversation about the theory by asking, "can you think of spaces and times in which this theory can be shown to be contingent or non-explanatory?" Students bring up examples and scenes of a crowded bus, subway, or dance party where territorial spaces begin to shrink. Students learn how the theory that was satisfactory on one occasion may not be universally valid as it is contingent based on time and space. I go on to highlight that the explanatory power of theories is conditioned by historical, temporal, and cross-cultural understandings. This introduces students to abstract thinking skills and a preliminary step toward critical international relations theories that raise criticisms against mainstream theories (i.e., feminism, postcolonialism). For example, some literature suggests that 
the social construction of masculinity is associated with territorial identifications and representations of sovereignty and autonomy (Malmberg 2019; Spajji 2008). ${ }^{6}$ Instructors can explore ways to introduce feminist perspectives on the social construction of state sovereignty and territoriality, which mainstream approaches take for granted (Mann 2013; Weber 1995). This can lead to a class conversation on how and why such mainstream theories (including the theory of human territoriality) have historically emerged as gendered and Eurocentric representations of the world (Peterson 2004; Tickner 2005). By the end of the lecture, without using the word 'epistemology' (that some students might find scary), students are equipped with basic tools to critically think about the strengths and weaknesses of theoretical analysis and knowledge production in general.

One can also reflect on the potential impact of space and audience on the distances and angles of the participants in the exercise vis-à-vis the audience. For example, I asked the volunteers to stand in various parts of the classroom in different courses to gauge the effect. The one place that satisfied me was when the volunteers were asked to perform in the middle of the audience where the audience themselves did not represent a viewing bloc. The volunteers were at the center of the classroom, where their classmates surrounded them, and there was no 'frontstage effect.' In all these different locales, students remained at a similar physical distance and roughly comparable angles to the one portrayed in Figure 1, which slightly fluctuates based on the atmosphere in a particular classroom. ${ }^{7}$ Given the pandemic year, one might also think about how the awareness of social distance might impact future exercises and how it might be easier to help students comprehend the theory.

\section{Conclusion}


Acknowledging the challenges of using simulations in the classroom, Glazier suggests that "instead of investing a great deal of time and effort into running a complex simulation, I recommend developing low-intensity simulations" $(2011,375)$. Furthermore, Mendenhall and Tutunji suggest that alternative teaching methods should have "low preparation time, minimal resource requirements, and ease of integration with existing curricula" $(2018,440)$. Similarly, Asal, et al. (2018) have pointed out that using simple gimmicks can be effective in teaching political science methodology. This mini-simulation follows those valuable suggestions in that there is little to no preparation time, no extra resources required, and a low-intensity activity that students positively comment on in evaluations months after.

This mini-simulation is a simple but effective way to teach theories. The mini-simulation of territoriality shows how theories are very relevant and help us understand and contingently predict human behavior. During the debriefing stage discussion, the simulation also reveals to students that theories are not universal and are contingent in their explanations based on time, space, and culture. Given the pandemic experience, future exercises can be thought of and incorporated into lectures to show the workings of social space and its relation to behavior.

As a practitioner and observer across different student cultures, I experienced that the physical distance between the two volunteers varies. For example, with American students, the volunteers are comparatively more physically distant than volunteers from European and Middle Eastern students. Volunteers from latter cultures seem to stand slightly closer to one another while engaging in their conversation. Pedagogically, this highlights that the audience and the setting are important. We should continuously strive to relate to our students' geographic and cultural backgrounds to improve our teaching. 
This simulation can be used in introductory and specialized political science courses and other subfields as political theory and political sociology. Having used this teaching technique across different learning cultures, I recommend my colleagues consider using this, or similar learning techniques, to assist students in achieving learning objectives.

\section{References}

Allee, Todd L., and Paul K. Huth. 2006. "Legitimizing Dispute Settlement: International Legal Rulings as Domestic Political Cover." American Political Science Review, 219-34.

Allison, Graham. and Philip Zelikow. 1999. Essence of Decision: Explaining the Cuban Missile Crisis. $2^{\text {nd }}$ edition. Longman.

Anderson, Benedict. 2006. Imagined Communities: Reflections on the Origin and Spread of Nationalism. Verso Books.

Asal, Victor, and Elizabeth L. Blake. 2006. "Creating Simulations for Political Science Education.” Journal of Political Science Education 2 (1): 1-18.

---------, and Jayson Kratoville. 2013. "Constructing International Relations Simulations: Examining the Pedagogy of IR Simulations through a Constructivist Learning Theory Lens." Journal of Political Science Education 9 (2): 132-43.

--------, Nina A. Kollars, Chad Raymond, and Amanda M Rosen. 2013. "Editors' Introduction to the Thematic Issue: Bringing Interactive Simulations into the Political Science Classroom." Journal of Political Science Education 9 (2): 129-31.

---------, Nakissa Jahanbani, Donnett Lee, and Jiacheng Ren. 2018. "Mini-Games for Teaching Political Science Methodology." PS: Political Science \& Politics 51 (4): 838-41.

Baranowski, Michael K., and Kimberly A. Weir. 2015. "Political Simulations: What We Know, What We Think We Know, and What We Still Need to Know." Journal of Political Science Education 11 (4): 391-403.

Butcher, Charity. 2012. "Teaching Foreign Policy Decision-Making Processes Using RolePlaying Simulations: The Case of US-Iranian Relations." International Studies Perspectives 13 (2): 176-94.

Caruson, Kiki. 2005. "So, You Want to Run for Elected Office? How to Engage Students in the Campaign Process without Leaving the Classroom." PS: Political Science and Politics 38 (2): 305-10.

Dyson-Hudson, Rada, and Eric Alden Smith. 1978. "Human territoriality: an ecological reassessment." American Anthropologist 80 (1): 21-41.

Ellington, Thomas C., Michael Grillo, and Carolyn Shaw. 2006. "Simulations and Role Playing (S\&RP) II Track Summary.” PS: Political Science and Politics 39 (3): 541-42. https://doi.org/10.1017/S1049096506300893.

Frederking, Brian. 2005. "Simulations and Student Learning." Journal of Political Science Education 1 (3): 385-93.

Glasgow, Sara M. 2014. "Stimulating Learning by Simulating Politics: Teaching Simulation Design in the Undergraduate Context." International Studies Perspectives 15 (4): 525-37. 
Glazier, Rebecca A. 2011. "Running Simulations without Ruining Your Life: Simple Ways to Incorporate Active Learning into Your Teaching." Journal of Political Science Education 7 (4): 375-93.

Guàrdia, Lourdes, Marcelo Maina, and Albert Sangrà. 2013. "MOOC design principles: A pedagogical approach from the learner's perspective." eLearning Papers 33.

Hamilton, Mark D. 2002. "'Networks of Power': A Simulation to Teach About Durable Inequality." Journal of Political Science Education 16 (1): 79-90.

Huth, Paul K. 2009. Standing your Ground: Territorial Disputes and International Conflict. University of Michigan Press.

Huth, Paul K., and Todd L. Allee. 2002. The Democratic Peace and Territorial Conflict in the Twentieth Century. No. 82. Cambridge University Press.

Johnson, Dominic DP, and Monica Duffy Toft. 2014. "Grounds for War: The Evolution of Territorial Conflict." International Security 38 (3): 7-38.

Jones, Rebecca, and Peter Bursens. 2015. "The Effects of Active Learning Environments: How Simulations Trigger Affective Learning." European Political Science 14: 254-65.

Krain, Matthew, and Christina J. Shadle. 2006. "Starving for Knowledge: An Active Learning Approach to Teaching about World Hunger.” International Studies Perspectives 7 (1): 5166.

Malmberg, Torsten. 2019. Human Territoriality: Survey on the Behavioural Territories in Man with Preliminary Analysis and Discussion of Meaning. Vol. 33. Walter de Gruyter GmbH \& Co KG.

Mann, Bonnie. 2013. Sovereign Masculinity: Gender Lessons from the War on Terror. Oxford University Press.

Omelicheva, Mariya Y., and Olga Avdeyeva. 2008. "Teaching with Lecture or Debate? Testing the Effectiveness of Traditional versus Active Learning Methods of Instruction." PS:

Political Science \& Politics 41 (3): 603-7.

Peterson, Spike. 2004. "Feminist Theories Within, Invisible To, and Beyond IR" The Brown Journal of World Affairs 10(2): 35-46.

Roberts, Joseph W. 2017. "Review of Active Learning in Political Science Blog." 109-11.

Ruggie, John Gerard. 1993. "Territoriality and Beyond: Problematizing Modernity in

International Relations." International Organization, 139-74.

Sack, Robert David. 1986. Human territoriality: Its theory and history. Vol. 7. CUP Archive. Senese, Paul D., and John A. Vasquez. 2008. The Steps to War: An Empirical Study. Princeton University Press.

Shellman, Stephen M, and Kürşad Turan. 2006. "Do Simulations Enhance Student Learning? An Empirical Evaluation of an IR Simulation.” Journal of Political Science Education 2 (1): 19-32.

Spaaij, Ramón. 2008. "Men like us, boys like them: Violence, masculinity, and collective identity in football hooliganism." Journal of Sport and Social Issues 32 (4): 369-92.

Tagma, Halit M.E., and Lenze Paul. 2020. Understanding and Explaining the Iranian Nuclear 'Crisis': Theoretical Approaches. Lexington Press.

Taylor, Kirsten. 2013. "Simulations Inside and Outside the IR Classroom: A Comparative Analysis." International Studies Perspectives 14 (2): 134-49.

Tickner, J. Ann. 2005. "Gendering a discipline: Some feminist methodological contributions to international relations." Signs: Journal of Women in Culture and Society 30 (4): 2173-2188. 
Vasquez, John A. 1995. "Why do Neighbors Fight? Proximity, Interaction, or

Territoriality." Journal of Peace Research 32 (3): 277-93.

Weber, Cynthia. 1995. Simulating Sovereignty: Intervention, the State and Symbolic Exchange. Cambridge University Press.

Wedig, Timothy. 2010. "Getting the Most from Classroom Simulations: Strategies for Maximizing Learning Outcomes.” PS: Political Science \& Politics 43 (3): 547-55.

Wunische, Adam. 2019. "Lecture Versus Simulation: Testing the Long-Term Effects." Journal of Political Science Education 15 (1): 37-48.

\section{Endnotes}

${ }^{1}$ I thank an anonymous reviewer for this.

${ }^{2}$ This simulation was conducted in thirty-three introductory and advanced level courses between 2006-2020.

Twenty-six of these courses were at an introductory level averaging fifty students. Seven of these classes were junior/senior-level averaging eighteen students. The size of the total student body was around 1500 students. I thank my earlier meetings with the late Richard Ashley for refining this exercise. This article is in his memory. I also thank my graduate assistant $\mathrm{Yu}$ Cao for her assistance.

${ }^{3}$ At the end of the exercise, I ask the audience to applaud the volunteers for their time and energy, which they appreciate. I also ask the volunteers to see me after class, where I allow them to take notes from the PowerPoint slide and ask questions so that they are not hindered from learning through their volunteering.

${ }^{4}$ This scene is in Seinfeld Season 5, Episodes 18/19. Close Talker can be watched on YouTube, https://www.youtube.com/watch?v=sRZ5RpsytRA. (Accessed on November 23, 2019).

${ }^{5}$ Anecdotally, in one debriefing stage, a student from Argentina had a valuable experience. After the class ended, a student kindly asked me to correct my referral to "Falkland Islands" as "Malvinas Islands." Giving credit to his perspective, I reminded him how territoriality might help us understand the very "naming" of the islands. The student grinned and tellingly mentioned that although neither he nor his relatives had ever been to Malvinas, "it still felt like those islands belonged to his nation." This was a memorable pedagogical experience for the instructor and the student.

${ }^{6}$ As one anonymous reviewer suggested, instructors might pair different gender identities to see if there is any variation in the spaces and, if so, how it might be theorized from a feminist perspective. This could also serve as a further segue to introduce critical theories of IR.

${ }^{7}$ I thank an anonymous reviewer for this point. 